\title{
Indonesian as a Foreign Language: Developing the Cultural Based Teaching Material
}

\author{
Novi Anoegrajekti ${ }^{1}$, Sudartomo Macaryus ${ }^{2}$, Endah Imawati ${ }^{3}$, Sunarti Mustamar ${ }^{4}$, \\ Heru SP Saputra ${ }^{5}$, Agustina Dewi Setyari ${ }^{6}$ \\ ${ }^{1456}$ University of Jember, Indonesia \\ ${ }^{2}$ University of Sarjanawiyata Tamansiswa Yogyakarta, Indonesia \\ ${ }^{3}$ Teacher Training and Education Institute of Widya Darma Surabaya, Indonesia \\ ${ }^{1}$ novianoegrajekti.sastra@unej.ac.id, 2sudartomo@ustjogja.ac.id, \\ 3endahimawati@ikipwidyadarma.ac.id
}

\begin{abstract}
Ritual is the part of culture that has its own language. With the wide range of the media, everyone gets a chance to present the cultural show that is happening all over the world. The android technology is on the hands of those people who can do so. Therefore, the language that is used in a ritual has a potential to be used as the base of Indonesian for foreigners teaching material development. The use of ritual can also be the media of internalisation of culture that can be used to understand the context of the language. This paper aims to implement the ritual as the base to develop the Indonesian for foreigners teaching material. By using the text analysis method, the data is got by doing an observation and participation in a ritual. Data is classified based on its general and specific characteristics. Data interpretation is done by lexical and semantic. Lexical interpretation is done by counting the general lexicon that is needed by the foreigners and semantic interpretation is done by explaining the basic meaning and other variety of possible meanings. By doing so, the learners (foreigners) can predict the new shapes based on its basic form and morphologic process that is done systematically and based on a certain structure.
\end{abstract}

Keywords: lexical, ritual, semantic, technology

\section{PENDAHULUAN}

Bahasa Indonesia yang berasal dari bahasa Melayu telah menjadi bahasa kuat, memiliki penutur besar, dan berperan penting dalam diplomasi. Kalangan perguruan tinggi dan Badan Bahasa menaruh perhatian terhadap program Pengembangan Bahasa Indonesia untuk Penurut Asing (BIPA). Perhatian pemerintah menguat dengan dibentuknya Pusat Pengembangan Strategi dan Diplomasi Kebahasaan, pada masa pemerintahan Presiden Susilo Bambang Yudhoyono. Indonesia setiap tahun mengirim pengajar BIPA ke berbagai negara. Muhadjir Effendy pada saat menjabat sebagai Menteri Pendidikan dan Kebudayaan menyampaikan bahwa pengajar BIPA mengemban misi setara diplomat. Program pengembangan BIPA sekaligus menunjukkan tanggung jawab Indonesia sebagai bangsa Indonesia sebagai warga dunia. Sebagian pembelajar adalah diplomat asing dan mahasiswa asing yang melanjutkan studi di Indonesia. Daniel Ortiz dari Columbia berminat belajar bahasa Indonesia untuk studi 
Program S2 Teknik Kimia di Universitas Gadjah Mada Yogyakarta. Selain itu, banyak juga yang belajar bahasa Indonesia untuk berkarir dalam bidang militer, bisnis, dan ilmuwan di negaranya masing-masing [1].

Pembelajaran diupayakan menggunakan media yang kreatif dan inovatif. Model pembelajaran dengan menggunakan permainan, hasilnya lebih baik daripada pembelajaran tradisional [2]. Karena bahasa sebagai unsur budaya yang merasuki semua unsur yang lain,, belajar bahasa berarti juga belajar budaya. Dengan mengadopti pembelajaran pada lembaga pendidikan formal, pengembangan bahan ajar memerlukan ketersediaan guru, kurikulum, dan bahan ajar yang berwawasan budaya, terlebih kondisi budaya Indonesia yang beragam [3].

Teknologi digital menyediakan fasilitas e-learning yang dapat diakses mandiri melalui komputer [4]. Fasilitas tersebut dapat dimanfaatkan untuk pembelajaran secara mandiri atau di kelas. Pembelajar yang telah menguasai sejumlah kosa kata dan tata bahasa, dapat mendengarkan Youtube untuk mencobakan kompetensinya. Youtube menyediakan informasi verbal, nonverbal, dan dikemas estetis yang berpotensi meningkatkan kompetensi kebahasaan dan menghibur [5]. Hasil penelitian Manurung [6] menunjukkan bahwa penerapan bahan ajar berbasis internet yang kontekstual meningkatkan keterampilan berbicara siswa. Peningkatan keterampilan tampak dari tingkat partisipasi, presentasi, pertanyaan, jawaban, argumen, dan debat. Oleh karena itu, literasi teknologi informasi dan komunikasi (TIK) bagi pengajar menjadi imperatif untuk mendukung pembelajaran. Kesanggupan pengajar menggunakan TIK ditentukan oleh motivasi. Copriady [7] menawarkan solusi peningkatan penggunaan TIK pada negara berkembang dengan infrastruktur dan fasilitas memadai, perlu mengintegrasikan TIK ke dalam kurikulum pendidikan dan memfasilitasi pengenalan TIK ke dalam sistem pendidikan. Selanjutnya, pemangku kebijakan perlu melatih dan mendidik guru agar terbiasa memanfaatkan TIK dan menggunakannya dalam pembelajaran.

Selain Youtube dan e-learning, potensi lainnya adalah pembelajaran dengan menggunakan game. Hasil penelitian Alias, dkk. [8] menunjukkan bahwa game berkapasitas besar dan seluler cenderung menjadi tren dominan di masa depan. Para ahli "sangat setuju" bahwa video game berpotensi efektif untuk mengajarkan bahasa Melayu pada pelajar asing di Public Higher Education Institution (PHEI) yang dipilih. Saat ini media penggunaan bahasa semakin banyak dan beragam untuk terus mempertahankan kompetensi keterampilan kebahasan melalui penggunaan yang kontinyu. Seseorang yang jarang menggunakan keterampilan berbahasa asing, keterampilannya akan menurun dan akhirnya hilang. Kalangan mahasiswa cenderung berbahasa asing untuk tujuan akademik dan budaya [9]. Melalui media digital, pembelajar berpotensi menentukan tujuan dan merancang proses pembelajaran secara mandiri. Hasil penelitian Pammua, dkk. [10] menyatakan bahwa di antara strategi membaca global, peserta didik cenderung menggunakan strategi seperti menetapkan tujuan membaca, mempratinjau teks, menentukan bacaan, menyelesaikan informasi yang saling bertentangan, dan mengonfirmasikan prediksi.

Pembelajaran konvensional juga masih dipertahankan, seperti bahasa Arab di lingkungan pesantren yang terintegrasi dengan materi keagamaan. Hasil penelitian Weke [11] menyatakan bahwa pesantren menggunakan metode sorogan dan bandongan dan lazim berkaitan dengan materi kitab kuning. Untuk menjaga dan mengembangkan kompetensi bahasa Arab [12], pesantren menerapkan cara belajar aktif dan mengondisikan praktik penggunaan bahasa Arab di lingkungan pesantren. Tujuh waktu sholat dan lingkungan lainnya diciptakan untuk praktik berbahasa Arab, mulai dari kegiatan di dapur sampai diskusi pemecahan masalah yang menuntut cara berpikir kritis, sistematis, dan logis.

Pengembangan pembelajaran konvensional berpotensi dikembangkan di daerah-daerah yang menjadi destinasi wisata, seperti Bali, Banyuwangi, Borobudur, dan Yogyakarta yang 
waktu tinggal wisatawan asingnya relatif panjang. Iglesias [13] memfokuskan perhatian pada produk wisata bahasa. Produk wisata bahasa berpotensi menghasilkan destinasi seperti kampung bahasa yang menjadi laboratorium alam dalam berjalar berbagai bahasa yang ditawarkan. Kampung bahasa berpotesnsi mengembangkan model-model permainan konvensional seperti twister, tebak kata, rangkai kata, rakai pantun, dan permainan bahasa lainnya. Permainan twister telah dipraktikan Korolkova dkk [14] untuk meningkatkan kompetensi fonetik bahasa Rusia. Bentuk permainan yang cenderung kompetitif berpotensi meningkatkan kompetensi pembelajar secara cepat dan cermat. Kecepatan dipacu oleh pembatasan waktu mengujarkan dan kecermatan dipacu oleh keharusan melafalkan secara benar.

Penempatan ritual sebagai pengembangan materi program BIPA berdasarkan beberapa pertimbangan berikut. Pertama, salah satu unsur ritual adalah narasi verbal yang berpotensi menjadi paparan penggunaan bahasa untuk meningkatkan kompetensi bahasa pembelajar. Kedua, program BIPA memadukan pengetahun bahasa dalam konteks sosial budaya masyarakat pendukungnya. Ritual sebagai ekspresi budaya masyarakat menjadi salah satu ranah budaya yang diperlukan untuk memahami bahasa secara kontekstual. Ketiga, ritual memiliki sifat performatif yang dikemas dengan menggunakan kaidah-kaidah estetis. Dengan demikian penempatan ritual sebagai sumber pengembangan materi pembelajaran sekaligus memberikan hiburan bagi pembelajar. Keempat, ritual di Banyuwangi memiliki dua tipe, yaitu berbasis budaya rural agraris dan berbasis budaya bahari. Kedua tipe ritual tersebut masih terus diselenggarakan setiap tahun dan mendapat dukungan dari pemerintah Kabupaten Banyuwangi.

Disampaikan oleh Anoegrajekti [15] [16], bahwa sejak tahun 2012, semua kegiatan budaya di Banyuwangi disatukan dalam Calender Banyuwangi Festival dan tahun 2019 bernama Majestic Banyuwangi Festival 2019 yang memuat 99 kegiatan budaya. Saat ini berberapa kegiatan ritual disiarkan langsung melalui jaringan internet secara streaming. Kedua cara tersebut memudahkan pembelajar untuk memilih kegiatan yang diminati untuk disaksikan secara langsung dengan hadir di lokasi penyelenggaraan atau secara tidak langsung dengan menyaksikan siaran melalui streaming. Fasilitator dapat melakukan pendampingan dalam menentukan pilihan dan dalam mengikuti siaran langsung atau yang tersimpan di dunia maya.

\section{METODE PENELITIAN}

Penelitian ini difokuskan pada penyelenggaraan ritual berbasis budaya bahari dan lebih spesifik lagi, yaitu RPT Muncar. Unsur verbal yang dikembangkan sebagai materi program BIPA adalah sambutan Bupati Abdullah Azwar Anas yang hadir pada acara praritual, yaitu fishmarket. Sambutan disampaikan dua kali, yaitu pada festival gemar makan ikan dan pemberangkatan prosesi gitik sesaji dari Barak Kalimoro menuju Dermaga Muncar yang menjadi pusat kegiatan RPT. Sambutan cenderung disampaikan dengan menggunakan ragam formal yang tertata. Dengan demikian menjadi model pajanan bahasa yang baik, benar, dan komunikatif.

Penyediaan data dilakukan dengan teknik simak, yaitu menyimak dan merekam pidato, serta mentranskripsikannya. Data yang sudah ditranskripsi dipilah dengan menggunakan teknik bagi unsur langsung untuk mendapatkan satuan-satuan lingual paragraf dan klausaklausa yang berpotensi dimanfaatkan untuk pengembangan materi program BIPA. Penjelasan secara leksikal untuk mengawali pemahaman terhadap makna dilengkapi dengan penjelasan secara kontekstual dan kultural. Penjelasan dilakukan secara lintas data untuk mendapatkan pemahaman secara komprehensif. 


\section{HASIL DAN PEMBAHASAN}

RPT Muncar berlangsung Minggu, 15 September 2019 dengan tiga kegiatan, yaitu praritual, ritual, dan pascaritual. Praritual berupa pembentukan panitia, pasar malam, pembuatan gitik sesaji, iderbumi, festival fishmarket, prosesi gitik sesaji dari Barak Kalimoro menuju Dermaga Muncar, protokoler dan hiburan. Ritual diawali pemasangan pancing emas pada kepala kambing, prosesi gitik laut menuju Pelawangan, dan larung sesaji. Pascaritual berupa hiburan, yaitu pentas jaranan dan orkes. Penyajian materi BIPA berbasis RPT Muncar disampaikan dalam beberapa tahap. Pertama, tayangan pelaksanaan RPT yang dapat diambil dari internet, Youtube. Kedua, tayangan sambutan Bupati Banyuwangi Abdullah Azwar Anas (BA3), atau tayangan foto saat beliau berpidato pada acara RPT Muncar. Ketiga, sajian transkrip pidato BA3. Keempat, analisis klausa dan leksikon pidato BA3.

RPT Muncar merupakan kegiatan formal. Oleh karena itu, bahasa yang digunakan juga ragam formal. Sambutan Bupati tampak pada data berikut.

\begin{tabular}{|c|c|c|}
\hline No & Bagian & Transkrip \\
\hline 1 & Pembuka & Baik saudara sekalian yang saya hormati. \\
\hline 2 & $\begin{array}{l}\text { Isi 1: } \\
\text { 1) rasa senang berada } \\
\text { di Muncar yang } \\
\text { bersih } \\
\text { 2) kataman Quran } \\
\text { 3) berbagi hasil } \\
\text { tangkapan }\end{array}$ & $\begin{array}{l}\text { Mudah-mudahan bersihnya tempat ini bukan karena ada petik } \\
\text { laut dan fishmarket festival. Kemarin di Alas Purwo baru } \\
\text { kataman Quran karena Alas Purwo mulai halus jalannya dan } \\
\text { mulai ada kegiatan. Keimarin kita katam Quran } 4 \text { kali di Alas } \\
\text { Purwo dan hari ini mulai ada kegiatan di sana. Harapan saya, } \\
\text { kalau bisa seminggu sekali panjenengan kataman Quran di } \\
\text { Masjid-Masjid atau di Mushola sebagai bentuk syukur kita } \\
\text { supaya ikan terus datang. Kalau yang tidak bisa ngaji kula Pak } \\
\text { Bupati, tak sempat kula, bisa kirim ikan ke Mushola. }\end{array}$ \\
\hline 3 & $\begin{array}{l}\text { Isi 2: } \\
\text { 1) harapan } \\
\text { masyarakat } \\
\text { menjaga } \\
\text { kebersihan, } \\
\text { 2) pasar ikan } \\
\text { dilengkapi tempat } \\
\text { pembakaran ikan, } \\
\text { 3) menggunakan } \\
\text { tambler untuk } \\
\text { bekal minuman } \\
\text { agar dapat diisi } \\
\text { ulang }\end{array}$ & $\begin{array}{l}\text { Yang kudua, tolong kebersihan dijaga. Kalau perlu semua travel } \\
\text { agent sebelum meninggalkan Alas Purwo menuju yang lain-lain, } \\
\text { makan ikannya di sini. Kalau bisa di sini ada tempat } \\
\text { pembakaran ikan yang enak. Jadi tidak hanya ada orang jual } \\
\text { ikan tetapi juga ada orang yang membakar ikan. Kapal-kapal } \\
\text { tidak usah bawa minuman dari plastik. Bawa saja seperti ini, } \\
\text { tambler berisi air, sehingga dengan begitu langsung diminum. } \\
\text { Sehingga dengan demikian tidak ada plastik yang dibuang. } \\
\text { Kalau banyak plastik, ini ikan tidak akan datang. Tetapi kalau } \\
\text { plastik berkurang insyaallah ikan akan datang. Kalau semua } \\
\text { nelayan dan kita semua solid, kompak, untuk tidak buang } \\
\text { sampah sembarangan, insyaallah ikan akan banyak. Maka kalau } \\
\text { bisa NSI mensponsori semua nelayan punya tambler seperti ini. } \\
\text { Bawa yang besar. Ini kan sering saya isi. Dengan demikian } \\
\text { mudah-mudahan Muncar bisa dijaga dari kebersihan plastik. }\end{array}$ \\
\hline 4 & $\begin{array}{l}\text { Isi 3: } \\
\text { 1) RPT menguatkan } \\
\text { persatuan dan }\end{array}$ & $\begin{array}{l}\text { Yang terakhir, mudah-mudahan ini, kegiatan ini bisa menjadi } \\
\text { alat pemersatu para nelayan. Dimaknai petik laut ini sebagai } \\
\text { bentuk silaturahmi para nelayan. Yang kedua, harapan saya ada }\end{array}$ \\
\hline
\end{tabular}




\begin{tabular}{lcc}
\hline No & Bagian & Transkrip \\
\hline & $\begin{array}{c}\text { 2) ajang silaturahmi } \\
\text { nelayan }\end{array}$ & $\begin{array}{l}\text { syukuran. Kalau bisa setiap nelayan ada yang survei ke depan } \\
\text { sehingga ikannya semakin banyak. Kiranya ini saja. }\end{array}$
\end{tabular}

Frasa idiomatik/kontekstual merupakan konstruksi frasa yang memiliki muatan makna idiomatik dan atau kontekstual. Dalam pembahasan ini konteks yang dimaksudkan adalah dalam bidang budaya, khususnya RPT Muncar. Sambutan BA3 diawali sapaan yang dilanjutkan ekspresi kebanggaan dan harapan terhadap masyarakat Muncar, seperti tampak pada data berikut.

(1) Baik saudara sekalian yang saya hormati.

(2) Saya senang hari ini berada di tempat ini.

(3) Mudah-mudahan bersihnya tempat ini bukan karena ada petik laut dan

fishmarket festival.

Data (1) sapaan saudara sekalian bersifat fatis untuk menyebut masyarakat secara general. Frasa di tempat ini pada data (2) adalah Barak Kalimoro sebagai tempat penyelenggaraan Fishmarket Festival. Penyebab rasa senang tampak pada data (3) yaitu karena lokasi bersih. BA3 berharap kebersihan tidak hanya terjadi pada saat penyelenggaraan $R P T$ tetapi sepanjang tahun agar ikan mau datang.

Selanjutnya BA3 menyampaikan frekuensi kegiatan budaya yang berlangsung di Banyuwangi. Frekuensi tersebut berkaitan dengan 99 kegiatan budaya yang dipublikasi melalui CBF tahun 2019 yang diberi nama Majestic Banyuwangi Festival 2019. Ragam Yang Maha Esa, seperti tampak pada data berikut.

(4) Kemarin di Alas Purwo baru kataman Quran karena Alas Purwo mulai halus jalannya dan mulai ada kegiatan.

(5) Harapan saya para nelayan ini, sekarang musim ikan nggih?

(6) Kalau bisa seminggu sekali panjenengan kataman Quran di Masjid-Masjid atau di Mushola sebagai bentuk syukur kita supaya ikan terus datang.

(7) Kalau yang tidak bisa ngaji kula Pak Bupati, tak sempat kula, bisa kirim ikan ke Mushola.

Data (4) kegiatan kataman Quran, yaitu ungkapan syukur karena telah menyelesaikan proses pembacaan kitab suci Alquran. Penempatan di hutan tropis Alas Purwo sebagai promosi destinasi wisata baru yang menyimpan berbagai situs sejarah dan legenda. Infrastruktur jalan yang halus memudahkan dan menyamankan wisatawan menuju Alas Purwo. Frasa musim ikan pada data (5) adalah waktu yang baik bagi para nelayan untuk menangkap ikan. BA3 berharap pada musim ikan para nelayan bersyukur kepada Tuhan dengan cara menyelenggarakan kataman Quran yang dinyatakan pada data (6). Kegiatan tersebut dapat dilangsungkan di Masjid atau Mushola yang banyak terdapat di perkampungan nelayan Muncar. Bagi yang tidak bisa membaca Quran dapat melakukan kirim ikan ke Mushola seperti pada data (7). Akrivitas kirim ikan yang dimaksudkan adalah bersedekah dengan cara berbagi rezeki melalui pengurus Masjid atau Mushola. Semangat berbagi ini diperlukan dalam rangka mewujudkan kesejahteraan bersama.

Peluang peningkatan kesejahteraan bersama juga ditawarkan kepada masyarakat dengan menjadikan Muncar sebagai destinasi wisata. Hal tersebut menuntut prasyarat menjaga kebersihan pantai dan laut. Tawaran menjadikan Muncar sebagai destinasi wisata dan ajakan menjaga kebersihan tampak pada data berikut.

(8) Yang kedua tolong kebersihan dijaga. 
(9) Kalau perlu semua travel agent sebelum meninggalkan Alas Purwo menuju yang lain-lain, makan ikannya di sini.

(10) Kalau bisa di sini ada tempat pembakaran ikan yang enak.

(11) Jadi tidak hanya ada orang jual ikan tetapi juga ada orang yang membakar ikan.

(12) Dengan demikian mudah-mudahan Muncar bisa dijaga dari kebersihan plastik.

Klausa kebersihan dijaga pada data (8) sebagai ajakan kepada masyarakat untuk menjaga kebersihan sebagai prasyarat menghadirkan wisatawan untuk menikmati kuliner ikan laut, seperti pada data (9) yang dinyatakan dalam konstruksi predikatif makan ikannya di sini. Wisata kuliner memberi pengalaman kepada wisatawan untuk membakar ikan. Frasa di sini yang dimaksud adalah Pantai Muncar. Tawaran tersebut memberi peluang masyarakat untuk membuka lahan pekerjaan dan areal kuliner pembakaran ikan seperti pada data (10). Tawaran tersebut memerlukan kesiapan lokasi, modal, pengorganisasian, dan kerja sama lintas bidang, seperti pemasok ikan, pengusaha kuliner, dan tenaga terampil yang mengolah ikan. Usaha kuliner pembakaran ikan juga merupakan diversifikasi usaha yang berpotensi meningkatkan kesejahteraan masyarakat nelayan seperti dinyatakan pada data (11), yaitu dari semula hanya jual ikan bertambah dengan kegiatan membakar ikan. BA3 menekankan lagi secara lebih spesifik mengenai prasyarakat kebersihan utamanya dari kebersihan plastik yang tampak pada data (12). Ajakan tersebut antara lain dieksplisitkan agar para nelayan membawa bekal minuman dengan menggunakan tambler seperti yang dilakukan oleh BA3.

BA3 mengakhiri sambutannya dengan dengan menyampaikan ajakan seperti tampak pada data (13) dan (14) berikut.

(13) Yang terakhir, mudah-mudahan ini, kegiatan ini bisa menjadi alat pemersatu para nelayan.

(14) Kiranya ini saja.

BA3 mengajak masyarakat menjadikan RPT sebagai alat pemersatu para nelayan, seperti pada data (13). Potensi pemersatu terbangun melalui kerja sama masyarakat, panitia, pemerintah setempat, pengusaha, dan Dinas Perikanan dan Kelautan. Semua komponen masyarakat terlibat dan hadir pada pelaksanaan RPT. Lima puluhan kapal yang mengangkut antara 50-60 penumpang mengikuti perjalanan prosesi laut mengiringi perjalanan kapal pembawa gitik sesaji. Dengan demikian ribuan warga masyarakat terlibat langsung dalam kegiatan RPT Muncar. Data (14) untuk mengakhiri sambutan disampaikan dengan konstruksi frasal kiranya ini saja yang mengandung maksud berbagai ajakan yang disampaikan pada sambutan, yaitu (1) menjaga kebersihan pantai, (2) bersyukur kepada Tuhan, (3) berbagi rezeki untuk sesama yang memerlukan, dan (4) melakukan diversifikasi usaha.

\section{SIMPULAN}

Pengembangan materi program BIPA berbasis RPT menyajikan materi pada tataran frasa dan klausa. Secara kontekstual, masing-masing menyampaikan sikap hormat, informasi, perintah, dan harapan. Sedangkan secara kewacanaan, pidato BA3 memberikan informasi prestasi Banyuwangi dan edukasi untuk terus mengembangkan Banyuwangi sebagai destinasi wisata dengan unggulan wisata alam, budaya, dan kuliner. Pengembangan kuliner sebagai salah satu bentuk diversifikasi usaha yang berpotensi meningkatkan kesejahteraan masyarakat muncar. Edukasi yang disampaikan BA3 adalah menjaga kebersihan pantai, bersyukur kepada Tuhan, berbagi rezeki, dan mendiversifikasi usaha. Pemaknaan secara kontekstual tersebut memperluas pemahaman pembelajar BIPA dalam bidang budaya bahari. Oleh karena itu, 
fasilitator program BIPA memerlukan rujukan yang lengkap dan bervariasi mengenai budaya bahari di Indonesia.

\section{REFERENCES}

[1] N. Sucahyo, "Bahasa Indonesia Makin Diminati Orang Asing," VOAINDONESIA.COM, 2019.

[2] D. Rawendy, Y. Ying, Y. Arifin, and K. Rosalin, "Design and Development Game Chinese Language Learning with Gamification and Using Mnemonic Method," Procedia Comput. Sci., vol. 116, 2017.

[3] F. Rokhman and Yuliati, "The development of the Indonesian teaching material based on multicural context by using sociolinguistic approach at junior high school," Procedia - Soc. Behav. Sci., vol. 9, 2010.

[4] A. H. M. Adnan and Z. M. Zamari, "Computer-Aided Self-Access Language Learning: Views of Indonesian, Malaysian \& New Zealand Practitioners," Procedia Soc. Behav. Sci., vol. 67, no. November 2011, 2012.

[5] B. Ghasemi, M. Hashemi, and S. H. Bardine, "UTube and language learning," Procedia - Soc. Behav. Sci., vol. 28, 2011.

[6] K. Manurung, "Improving the Speaking Skill Using Reading Contextual Internetbased Instructional Materials in an EFL Class in Indonesia," Procedia - Soc. Behav. Sci., vol. 176, 2015.

[7] J. Copriady, "Self - Motivation as a mediator for teachers' readiness in applying ICT in teaching and learning," Turkish Online J. Educ. Technol., vol. 13, no. 4, 2014.

[8] N. Alias, F. Rosman, M. N. A. Rahman, and D. Dewitt, "The Potential of Video Game in Malay Language Learning for Foreign Students in a Public Higher Education Institution," Procedia - Soc. Behav. Sci., vol. 176, 2015.

[9] R. Setiadi and A. Piyakun, "Foreign literacy practices and learning skills among Indonesian and Thai students of graduate education studies," Kasetsart J. Soc. Sci., 2018.

[10] A. Pammu, Z. Amir, and T. N. R. T. M. Maasum, "Metacognitive Reading Strategies of Less Proficient Tertiary Learners: A Case Study of EFL Learners at a Public University in Makassar, Indonesia," Procedia - Soc. Behav. Sci., vol. 118, 2014.

[11] I. S. Wekke, "Arabic Teaching and Learning: A Model from Indonesian Muslim Minority," Procedia - Soc. Behav. Sci., vol. 191, 2015.

[12] M. Yusuf and I. S. Wekke, "Active Learning on Teaching Arabic for Special Purpose in Indonesian Pesantren," Procedia - Soc. Behav. Sci., vol. 191, 2015.

[13] M. Iglesias, "Language Travel Supply: The Language Learning Programme," Procedia - Soc. Behav. Sci., vol. 232, no. April, 2016.

[14] Y. V. Korolkova, O. A. Slabukho, V. V. Vydrina, A. N. Zheleznyakova, and L. Zhang, "Effective Techniques for Working with the Tongue Twister in the Elementary Level of Training Russian as a Foreign Language," Procedia - Soc. Behav. Sci., vol. 215, no. June, 2015.

[15] N. Anoegrajekti, S. Macaryus, M. S. Kusumah, L. Izzah, and S. G. Attas, "The Oral Tradition of Petik Laut Banyuwangi Revitalization of Tradition and Local-Global Political Space," KnE Soc. Sci., vol. 3, no. 9, 2018.

[16] N. Anoegrajekti, A. Sariono, S. Macaryus, and M. S. Kusumah, "Banyuwangi Ethno Carnival as visualization of tradition: The policy of culture and tradition revitalization through enhancement of innovation and locality-based creative industry," Cogent Arts Humanit., vol. 5, no. 1, 2018. 
